\title{
Fitness for Service Assessment of Ageing Pressure Vessel Experiencing External Corrosion: A Case Study
}

\author{
Enefola S. Ameh \\ Offshore Technology Institute, University of Port-Harcourt, Nigeria
}

\begin{abstract}
-
The aim of the present study was to establish integrity of pressurized vessel belonging to Shell Petroleum Development Company in Nigeria that experienced severe external corrosion. Fitness for service methodology according to API 579 using Level 1 and 2 was employed in the analysis of the ageing pressure vessel and the result of the evaluation indicated the external localized corrosion defect was within an acceptable boundary which implied the pressurized vessel was fit to continue in operation and still have 40 years remaining life based on the evaluated external corrosion defect present.
\end{abstract}

Keywords: Corrosion, Fitness for service, Pressure vessel.

Date of Submission: 16 January 2017

$\longrightarrow$

Date of Accepted: 09 February 2017

\section{INTRODUCTION}

Pressure vessel can be defined as separator or containment with a difference in pressure between the outside and inside environment. But most times the outside pressure is lesser than the inside pressure and these Pressure vessels are cylindrical in shape and used for hydrocarbon separation, fluid storage and pressure contaminant [1]. Pressurized pressure vessel equipment in the upstream of oil and gas industry usually experience in-service damage due to corrosion induced and process related issues [2]. One of the main leading causes of pressure vessels failure is localized corrosion [3] which has become a major threat in the oil and gas industry [4]. Consequences of pressure vessel failure due to corrosion and ageing sometimes lead to production loss, unintentional release, damage to adjacent structures, catastrophic effect of explosion and fire leading to fatalities and injuries to the public and workers [5]. Ageing pressure vessels are now serious concern in Nigeria oil and gas industry since the Nation economy mainstay is oil and has increasingly continued to increase her daily output production and income generation. Hence, many of the process equipment including pressure vessels are being pushed to operate beyond their intended design life.

Fitness for service (FSS) is a qualitative engineering assessment method for determining continued operation of pressure vessel equipment or retirement. American Petroleum Institute (API) published API 579 document in 2000 and then recommended fitness for service evaluation [6]. But American Society for Mechanical Engineer came together in 2007 to produce new standard document for FSS method, now known as API 579-1/ASME document for FSS-1. Evaluated integrity of pressure vessel components experiencing local hot spot adopting plasticity theory variation was studied. Remaining strength factor (RSF) empirical formula was proposed for the quantification of pressure vessel remaining strength using decay shell length for reference volume identification [7]. The remaining strength factor was applied to the theory of pressure vessel corrosion damage assessment of in-line pipeline [8]. While an overview of FSS assessment, analytical and technical fitness for service assessment of uniformly corroded pressure vessel using only Level 1 was performed. Based on the Level I corrosion assessment finding, the corrosion defect was within an acceptable boundary [9]. API 579 and British standard (BS) 7910 design codes and application to process piping under pressure condition on FSS with presence of longitudinal crack defect was studied. The API 597 and BS 7910 results were in agreement and showed the crack defects being evaluated were stable and within acceptable envelope. However, BS 7910 result appeared more conservative [10]. A Level 3 fitness for service assessment of cylindrical pressure vessel with both external and internal general corrosion was conducted. Finite element method with ANSYS software was used in transient analysis which was not taken into cognizance by the API 579 recommended practice. The results of Level 1 and 2 indicated equipment was not safely operated while Level 3 showed the contrary [11].

But fitness for service assessments of equipment using API 579 have been reported to give false results, consequently leading to several inspections and premature repairs which in turn increased the cost of production in the oil and gas industry. Several related previous works on fitness for service assessment of critical equipment with presence of defects conducted so far were silent on the age of equipment considered and whether the design life have been exceeded. Secondly, the presence of corrosion defect on ageing pressure vessel reduces reliability 
and life span of the equipment. The purpose of the present study, therefore, is to establish reliability of the ageing pressurized structure which experienced localized induced corrosion and ensure it is not subjected to severe operating condition than it was conceptually designed for using fitness for service method. The corrosion assessment analysis would help to fully utilize the potential damage asset and make informed decision in integrity maintenance adjustment, inspection scheduling frequency and avoid potential premature repair and retirement that comes with cost implication.

\subsection{Case Study}

\section{MATERIALS AND METHOD}

A case study of severely corroded horizontal pressure vessel belonging to Shell Petroleum Development Company in Nigeria was conducted. The large horizontal pressure vessel was manufactured from carbon steel and commissioned in 1975 to separate three phase streams which contain significant amount of free water, $\mathrm{CO}_{2}$, $\mathrm{H}_{2} \mathrm{~S}$ and other elements. The pressure vessel data are given as:

Material: A 516 Grade 70

Inside steel diameter: $900 \mathrm{~mm}$

Nominal thickness: $16.25 \mathrm{~mm}$

Corrosion allowance: $2.25 \mathrm{~mm}$

Design temperature: $60^{\circ} \mathrm{C}$

Design condition pressure: $2.5 \mathrm{MPa}$

Design life: 40 years

Allowable stress: $370 \mathrm{MPa}$

Weld efficiently factor: 0.85

A nondestructive examination and automated ultrasonic technique was employed in the inspection of horizontal pressure vessel. The automated ultrasonic testing machine continuously scanned over the suspected corrosion thinning area and the thickness profile at each grid point was recorded as shown in Table 1. The grid point inspection point was $50 \mathrm{~mm}$ equidistance for both longitudinal and circumferential distance. Analysis of the report revealed localized external corrosion mechanism. Fig 1 showed typical example of the pressure vessel grid inspection.

Table 1: Circumferential and longitudinal corrosion profile

\begin{tabular}{|c|c|c|c|c|c|c|c|c|c|}
\hline \multirow{2}{*}{$\begin{array}{l}\text { Longitudinal inspection } \\
\text { plane }\end{array}$} & \multicolumn{8}{|c|}{ Circumferential Inspection Plane } & \multirow[t]{2}{*}{ Circumferential CTP } \\
\hline & $\mathrm{C} 1$ & $\mathrm{C} 2$ & C3 & $\mathrm{C} 4$ & $\mathrm{C} 5$ & C6 & $\mathrm{C} 7$ & $\mathrm{C} 8$ & \\
\hline M1 & 16.25 & 16.25 & 16.25 & 16.25 & 16.25 & 16.25 & 16.25 & 16.25 & 16.25 \\
\hline M2 & 16.25 & 9.50 & 20.50 & 21.75 & 11.50 & 12.00 & 12.00 & 16.25 & 9.50 \\
\hline M3 & 16.25 & 11.75 & 12.25 & 11.25 & 12.25 & 12.50 & 12.50 & 16.25 & 11.25 \\
\hline M4 & 16.25 & 12.75 & 9.25 & 12.00 & 6.50 & 12.25 & 14.00 & 16.25 & 6.50 \\
\hline M5 & 16.25 & 13.00 & 12.25 & 12.00 & 11.75 & 9.75 & 13.25 & 16.00 & 9.75 \\
\hline M6 & 16.00 & 11.75 & 12.25 & 13.00 & 11.50 & 12.25 & 12.50 & 16.25 & 11.50 \\
\hline M7 & 16.00 & 9.50 & 16.25 & 16.00 & 6.75 & 6.75 & 9.50 & 16.25 & 6.75 \\
\hline LONGITUDINAL CTP & 16.00 & 9.50 & 9.25 & 11.25 & 6.75 & 6.50 & 9.50 & 16.00 & \\
\hline
\end{tabular}

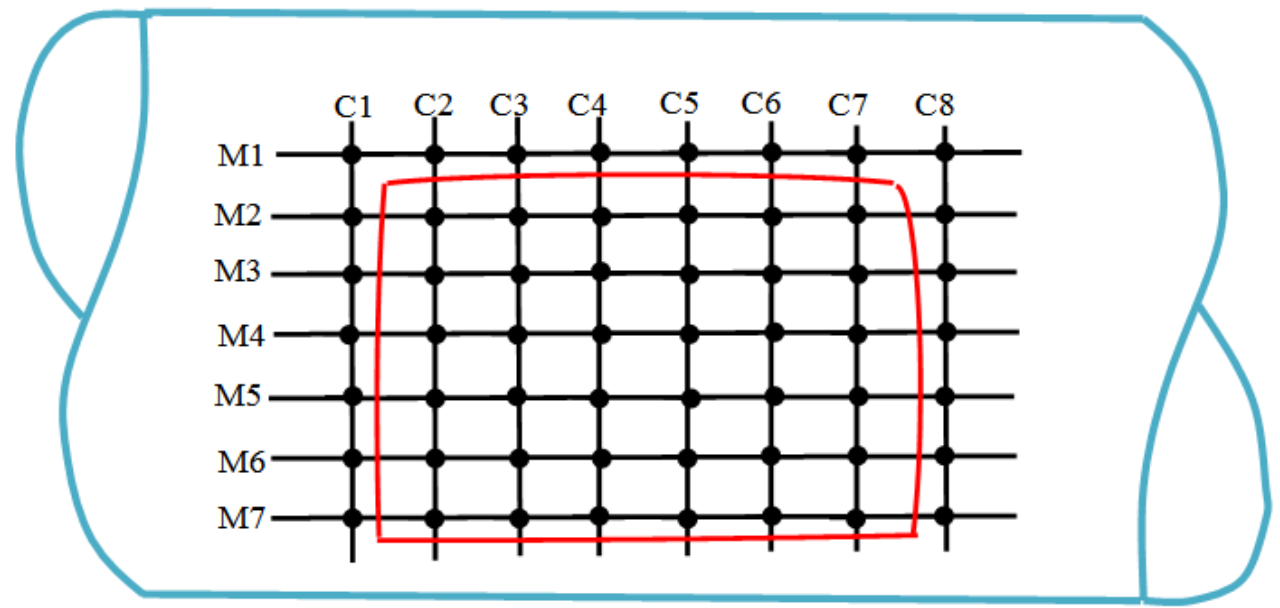

Figure 1: Inspection grid of corroded thinning area 


\subsection{Application of Fitness for Service Techniques}

A step-by-step approach was employed in evaluating the fitness for service of $900 \mathrm{~mm}$ diameter and $3000 \mathrm{~mm}$ long horizontal pressure vessel belonging to Shell Petroleum Development Company in Nigeria using American Petroleum Institutes (API) 579 code. Minimum required wall thickness at the circumferential and longitudinal planes are computed with mathematical expression:

$$
\begin{aligned}
& t_{\min }^{C}=\frac{P R_{c}}{(S E-0.6 P)} \\
& t_{\min }^{L}=\frac{P R_{\varepsilon}}{(2 S E+0.4 P)}
\end{aligned}
$$

Where, $E=$ weld efficient factor, $S=$ material allowable stress, $P=$ maximum design pressure, and $R_{\varepsilon}$ is defined as pressure vessel radius and as:

$$
\begin{aligned}
& R_{c}=R+F C A \\
& \quad=450+2.25=452.25 \\
& t_{\min }^{C}=\frac{2.5 \times 452.25}{(370 \times .85)-(0.6 \times 2.5)}=3.61 \mathrm{~mm} \\
& t_{\min }^{L}=\frac{2.5 \times 452.25}{(2 \times 370 \times .85)+(0.4 \times 2.5)}=1.80 \mathrm{~mm}
\end{aligned}
$$

The maximum value between $t_{\min }^{C}$ and $t_{\min }^{L}$ is used in the estimation of remaining wall thickness ratio expressed as:

$R_{t}=\frac{t_{m m}-F C A}{t_{\min }}$

where, future corrosion allowance $(F C A)$ is given as $2.25 \mathrm{~mm}$ and the minimum thickness reading $\left(t_{\text {mmm }}\right)$ obtained during Ultrasonic inspection of the pressure vessel indicated in Table 1 is $6.50 \mathrm{~mm}$.

$R_{t}=\frac{6.50-2.25}{3.61}=1.18$

According to API 579, average thickness length is computed next and is given as:

$L=Q \sqrt{D t_{\min }}$

where, $D$ is pressure vessel internal diameter and $Q$ is a factor computed with the expression:

$Q=1.123\left\{\left[\frac{1-R_{t}}{1-\left(R_{t} / R S F_{a}\right)}\right]^{2}\right\}^{1 / 2}$

where, the allowable remaining strength factor $\left(R S F_{a}\right)$ is assumed to be 0.9 for pressure vessel according to the code.

$Q=1.123\left\{\left[\frac{1-1.18}{1-(1.18 / 0.9)}\right]^{2}\right\}^{1 / 2}=0.67$

Average thickness length, $L$ :

$L=0.67 \sqrt{900 \times 3.61=38 .}=38.19 \mathrm{~mm}$

Next step is to compute average measured thickness $t_{\min }^{L}$ of the longitudinal critical thickness profile (CTP) Fig 2 and $t_{\min }^{\complement}$ of the circumferential critical thickness profile (CTP) Fig 3 as follows:

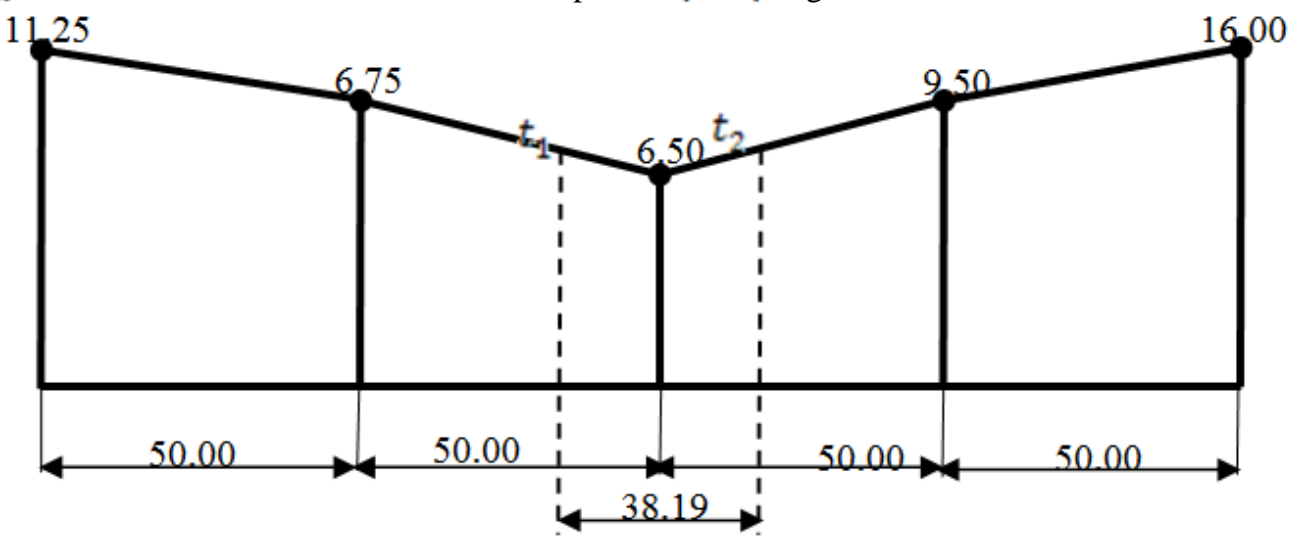

Figure 2: Longitudinal critical thickness profile 
$t_{1}=6.50+(6.75-6.50)\left[\frac{19.095}{50.000}\right]=6.596 \mathrm{~mm}$

$t_{2}=6.50+(9.50-6.50)\left[\frac{19.095}{50.000}\right]=7.646 \mathrm{~mm}$

Area method for estimating the average measured thickness is:

$A_{1}=\frac{6.596+6.50}{2}[19.095]=125.034 \mathrm{~mm}^{2}$

$A_{2}=\frac{7.646+6.50}{2}[19.095]=135.059 \mathrm{~mm}^{2}$

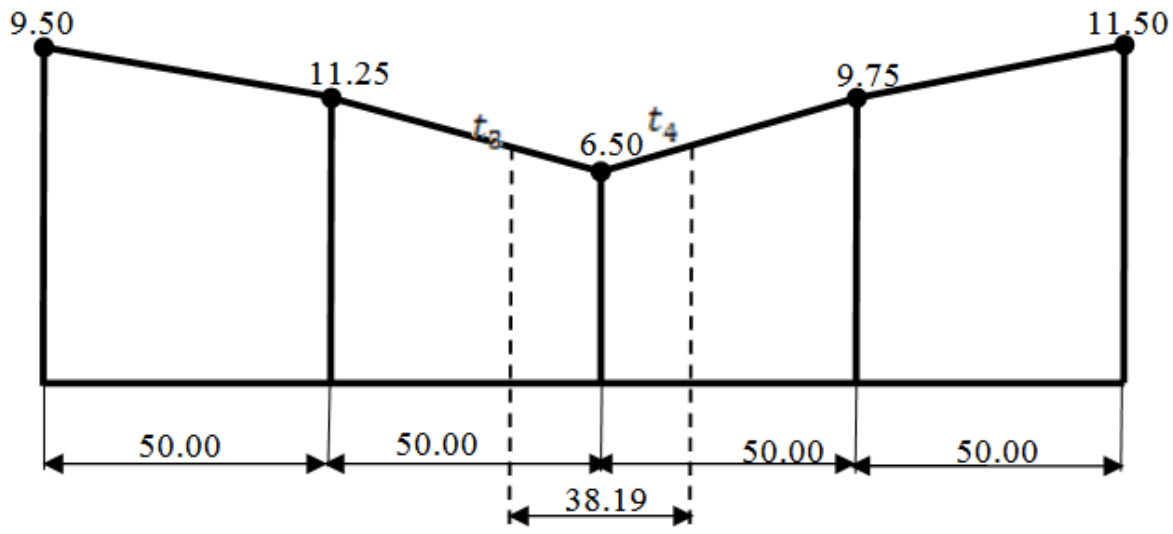

Figure 3: Circumferential critical thickness profile (mm)

$t_{3}=6.50+(11.25-6.50)\left[\frac{19.095}{50.000}\right]=8.315 \mathrm{~mm}$

$t_{4}=6.50+(9.75-6.50)\left[\frac{19.095}{50.000}\right]=7.742 \mathrm{~mm}$

$A_{3}=\frac{8.315+6.50}{2}[19.095]=141.446 \mathrm{~mm}^{2}$

$A_{4}=\frac{7.742+6.50}{2}[19.095]=135.976 \mathrm{~mm}^{2}$

Average measured thickness $t_{\min }^{L}$ and $t_{\min }^{C}$ based on the longitudinal and circumferential critical thickness profile respectively are computed with the following equations:

$t_{a m}^{L}=\frac{A_{1}+A_{2}}{L}$

$t_{a m}^{c}=\frac{A_{g}+A_{4}}{L}$

$t_{a m}^{L}=\frac{A_{1}+A_{2}}{L}=\frac{125.034+135.059}{38.19}=6.81 \mathrm{~mm}$

$$
t_{a m}^{c}=\frac{A_{8}+A_{4}}{L}=\frac{141.446+135.976}{38.19}=7.26 \mathrm{~mm}
$$

Level 1 and Level 2 acceptability criteria for external corrosion for continue operations are given in equations (9) and (10) respectively:

$t_{a m}^{L}-F C A>t_{\min }^{c}$

$t_{a m}^{c}-F C A>t_{\min }^{L}$

$t_{a m}^{L}-F C A \geq R S F_{a} \times t_{\min }^{c}$

\subsubsection{Remaining Life}

Remaining life of the pressure vessel with severe external corrosion was assessed and determined with equations (11) and (12) respectively as shown below:

Corrosion Rate $=\frac{T_{\text {initial }}-T_{\text {last }}}{\text { Years between initial and last inspection }}$

Remaining Life $=\frac{T_{\text {initial }}-T_{\text {minimum }}}{\text { Corrosion Rate }}$

where, $T_{\text {initial }}={ }_{\text {original wall thickness as-received }}$ 
$T_{\text {initial }}=$ most recent wall thickness measured

$T_{\text {minimum }}=$ Minimum wall thickness measured

Corrosion Rate $=\frac{16.25-6.50}{40 y \mathrm{rs}}=\frac{0.24 \mathrm{~mm}}{\mathrm{yr}}$

Remaining Life $=\frac{16.25-6.50}{0.24}=40$ years

\section{DISCUSSION}

The average measured thickness on the longitudinal $\left(t_{\mathrm{min}}^{L}\right)$ and circumferential $\left(t_{\mathrm{min}}^{C}\right)$ critical thickness of the external corrosion profile were calculated as $6.81 \mathrm{~mm}$ and $7.26 \mathrm{~mm}$ respectively according to equations (7) and (8). Acceptability criteria for Level 1 and Level 2 fitness for service assessment for external corrosion were validated using equations (9) and (10). The results of the fitness for service evaluation for the 900mm diameter and 3000mm long cylindrical horizontal pressure passed Level 1 and Level 2 acceptability criteria. The FSS analysis proved the equipment was permitted to continue in operation at its designed maximum allowable working pressure of $2.5 \mathrm{MPa}$ without the need for rerating. Given the age of the pressure vessel and the severe physical presence of localized thinning external corrosion, the equipment might have been forced to be rerated, repaired or retired prematurely. But the fitness for service evaluation results indicated healthy equipment that was still fit for use and operational continuity regardless of the corrosion flaw presence. Remaining life of the pressure vessel was also evaluated to establish inspection frequency and prioritize turnaround maintenance relative to other process equipment in other facilities. The remaining life of the equipment based on the current existing corrosion defect was computed as 40 years. This implied that the pressure vessel can continue to be operated or remained in service for the next 40 years based on the present defect.

\section{CONCLUSION}

The applicability and criticality analysis of the Level 1 and Level 2 fitness for service assessment according to API 579 for the external corrosion found in the pressure vessel proved the equipment was safe for continued operation without any impact on the safety and environment. The fitness for service evaluation of corrosion related defect and ageing process equipment in the oil and gas industry is a necessary assessment before taking decisive decision on rerating, repair and retirement no matter how the visual inspection and instrumented nondestructive examination results may appear. The critical fitness for service assessment conducted on the pressure vessel equipment helped to eliminate unnecessary turnaround maintenance and inspections that would have incurred cost and impacted on business. However, even though the results showed the equipment was safe to continue in operation and has remaining life of 40 years, it was suggested the localized corrosion be monitored and insulated from corrosive environment to prevent further corrosion.

\section{REFERENCES}

[1]. B. S. Thakker and S. A. Thakker, Design of Pressure vessel ASME Code, Section VIII, Division 1, International Journal of Advance Engineering Research and Studies, Vol 1, Issue II, 2012, pp 228-234.

[2]. F. Vicente, Mechanical Integrity Assessment of a Large Horizontal NGL Pressure Vessel: Case Study, Article on Maintenance and Asset Management, Vol 25, No. 5, 2010.

[3]. M. A. Nessim, W. Zhou, J. Zhou, B. Rethwell and M. Mclamb, Target Reliability Level for Design and Assessment of Onshore National Gas Pipeline, Journal of Pressure Vessel Technology, ASME, Vol 6, 2009, Pp 1-12.

[4]. P. R. Roberge, Handbook of corrosion Engineering (Pub. McGraw-Hill, New York 2000).

[5]. F. A. Simonen, Pressure Vessels and Piping System: Reliability, Risk and Safety Assessment, Article on Desalination and water Resources, pacific Northwest National Laboratory, Richland, USA, 2007.

[6]. Fitness for Service, API Recommended Practice 579, (American Petroleum Institutes, Washington DC, USA, 2000)

[7]. R. Seshadri, Integrity Assessment of Pressure Component with Local Hot Sport, Journal of Pressure Vessel Technology, 2005, 127:137e42.

[8]. H. Indermohan and R. Seshadri, Fitness for service methodology based on Vibrational Principle in Plasticity, Journal of Pressure Vessel Technology, 2005, 127:92e7

[9]. U. C. Dorinel, The Inspection and Evaluation of the Technical Estate of a Recipient Affected by Corrosion using the API RP 579, Standard, Concept of Broking Mechanical and the Principle of Critical Energy, Journal of Engineering Studies and Research, Vol 18, No. 3, 2012.

[10]. F. Giacobbe, D. Geraci, E. Biancuzzo and M. Albino, Maintenance Engineering: Case Study of Fitness for Service Assessments, International Conference on Engineering Design, ICED II, Technical University of Denmark, 2011.

[11]. J. I. L. Almeida, M. C. Rodrigues and K. O. V. Mishna, Modelling and Level 3 Fitness for Service Assessment of a Cylindrical Pressure Vessel with General Metal Loss in Conjunction with Numerical Thermal transient Analysis, International Journal of Mechanics and Application, Vol 4, 2014, Pp 80-93. 